\title{
High Grade Penile Intraepithelial Neoplasia
}

National Cancer Institute

\section{Source}

National Cancer Institute. High Grade Penile Intraepithelial Neoplasia. NCI Thesaurus.

Code C7667.

Penile intraepithelial neoplasia characterized by the proliferation of transformed basaloid cells that occupy either the lower two thirds of the epithelial thickness (grade II) or the entire thickness of the epithelium (grade III, Bowen atypia, or squamous cell carcinoma in situ). 